\title{
LA TRADUCCIÓN EDITORIAL EN ESPAÑA: DEMANDAS Y COMPETENCIAS PROFESIONALES DEL TRADUCTOR DE LIBROS EN LOS ÁMBITOS FILOSÓFICO Y SOCIOPOLÍTICO
}

\author{
Mercedes Enríquez-Aranda* \\ Universidad de Málaga
}

\begin{abstract}
Resumen: La traducción de libros en los ámbitos filosófico y sociopolítico se enmarca profesionalmente dentro de la traducción editorial. Si bien esta actividad traductora supone una parte importante de la producción editorial en el mercado español actual, hasta el momento se ha prestado poca atención a su estudio en relación con las demandas y competencias profesionales que definen la tarea del traductor. Por esta razón, en este artículo se pretenden conseguir dos objetivos: actualizar la definición de los textos sociopolíticos y filosóficos desde su clasificación genérica a partir de la descripción de sus rasgos más distintivos y conducir esta disertación al terreno laboral, en el que se exige al traductor de estos textos un perfecto desarrollo de competencias profesionales que deben adaptarse a las características de un entorno laboral cambiante. Aspectos como la diacronía en la traducción, los métodos traductores, los formatos de publicación y la oralidad en la traducción se esbozan como principales demandas editoriales. El traductor desarrolla así competencias profesionales específicas para llevar a cabo un amplio rango de tareas relacionadas no solo con la carga cultural e ideológica de los textos que maneja sino en gran medida con el contexto en el que se inserta su actividad y con los participantes en el proceso de traducción.
\end{abstract} Palabras clave: Traducción editorial. Profesión del traductor. Traducción de textos sociopolíticos y filosóficos.

\footnotetext{
* Mercedes Enríquez-Aranda studied Translation and Interpreting at the University of Malaga (Spain), where she was awarded an Extraordinary Prize for her PhD in Translation and Interpreting in 2005. She is now a Reader in English language and culture and translation and interpreting (English-Spanish-English) at the University of Malaga. Malaga, Spain. E-mail: mmenriquez@uma.es.
} 


\title{
TRANSLATING FOR THE PUBLISHING WORLD IN SPAIN: PROFESSIONAL DEMANDS AND COMPETENCES OF THE TRANSLATOR OF BOOKS ON PHILOSOPHICAL AND SOCIOPOLITICAL DOMAINS
}

\begin{abstract}
The translation of books on philosophical and sociopolitical domains is professionally set within the boundaries of translation for the publishing world. Although this translating activity plays an important role in the current Spanish publishing industry, it has been barely studied in relation to the professional demands and competences that define the translator's task. Consequently, this article has two main goals: first, bringing the definition of sociopolitical and philosophical texts up to date from the study of their genre features, and, second, connecting this theoretical reflection to the work setting, in which the translator is asked to develop a whole range of professional competences easily adaptable to the changing publishing world. The diachrony in translation, the translation methods, the publishing formats and the orality in translation are dealt with as being the leading professional demands. Thus the translator needs to meet specific professional competences targeted towards the fulfillment of a wide range of tasks related not only to the cultural and ideological burden of the texts to be translated but also related to the translation context and the participants in the translation process.
\end{abstract}

Keywords: Translation for the Publishing World. Translator's Profession. Translation of sociopolitical and philosophical texts.

\section{Definición actualizada de los textos sociopolíticos y filosóficos}

\subsection{Clasificación genérica}

Los estudios literarios actuales salvan las dos posturas tradicionales relativas a la definición del género literario, a saber, aquella que considera el género literario como norma preceptiva que se ha de respetar (postura clásica) y aquella que considera el género literario como pauta que se puede trasgredir (postura romántica), para considerar el género literario como una configuración diná- 
mica de convenciones temáticas y discursivas que colabora en la clasificación de los textos orales y escritos producidos en diferentes culturas (Enríquez-Aranda y Mendoza García, 2014, en prensa).

Esta flexible y nueva percepción del género literario permite sistematizar el estudio de aquellos textos cuya clasificación genérica resulta especialmente conflictiva. Es el caso de los textos cuyo contenido no es de carácter ficcional sino doctrinal. Al amparo de esta clasificación genérica por tema se hallan los textos humanísticos, que tratan de aspectos relativos a las ciencias humanas y sociales (García Berrio y Huerta Calvo, 1992, 218-230).

Los textos sociopolíticos y filosóficos, por consiguiente, se adscriben al género humanístico en tanto tratan temas concernientes al ser humano y a sus relaciones sociales.

\subsection{Rasgos distintivos}

Los textos sociopolíticos y filosóficos, como textos humanísticos merecedores de su propia clasificación genérica, presentan, sin embargo, rasgos distintivos formales comunes a los textos literarios. Su marcada función didáctica, que favorece una mayor presencia de la función apelativa, condiciona un embellecimiento estético del mensaje que se presenta como objetivo, aunque sesgado por la subjetividad del emisor. Las funciones poética y expresiva llegan a encapsular a la función referencial dando como resultado un texto cuyas características se enmarcan en las propias de la comunicación literaria.

Los textos sociopolíticos, que versan sobre aspectos conjuntos relativos a las sociedades y a sus políticas, y los textos filosóficos, que intentan ofrecer explicaciones racionales sobre el sentido de las actuaciones humanas, se revisten de formas genéricas de expresión dramática, de expresión objetiva y de expresión subjetiva en clara correspondencia con la tríada genérica clásica dramática, épica o narrativa y lírica, respectivamente (García Berrio y Huerta Calvo, 218-230). Sus formas pueden ser tanto oratorias como escritas, con 
preferencia por esta última, y el canal de transmisión no tiene por qué limitarse a la publicación editorial, aunque persiguen sin duda la perdurabilidad en el tiempo. El emisor de estos textos suele ser individual (al menos su firma, sino la responsabilidad completa del mensaje) y tiene en mente a un receptor colectivo más o menos identificado.

Estos rasgos distintivos generales difieren en función de cada texto sociopolítico y filosófico en particular y todos ellos deben estudiarse a partir de la definición de la obra de arte como obra abierta que Eco $(1990,74)$ defiende: “[...] una obra de arte, forma completa y cerrada en su perfección de organismo perfectamente calibrado, es asimismo abierta, posibilidad de ser interpretada de mil modos diversos sin que su irreproducible singularidad resulte por ello alterada".

\section{Entorno laboral de la traducción de textos sociopolíticos y filosóficos}

\subsection{Mercado editorial español actual}

La traducción de textos sociopolíticos y filosóficos en España en la actualidad se enmarca dentro del ámbito editorial y depende, por tanto, de las políticas de producción editorial que se aplican tanto a nivel general como en un campo temático muy concreto.

Desde el 1 de enero de 2012, la Agencia Española del ISBN, de acuerdo con las editoriales, las distribuidoras y las librerías españolas y con la coordinación de la Federación de Gremios de Editores de España (FGEE), realiza la clasificación por materias de la producción editorial española mediante el sistema internacional IBIC (International Book Industry Categories), que sustituye al antiguo sistema de clasificación CDU (Clasificación Decimal Universal). ${ }^{1}$ Según este listado (FGEE, 2011, 21-37), los textos sociopolíticos se encuadran en la categoría de materia J "Sociedad y ciencias sociales", identificados más concretamente con los có- 
digos de materia JF "Sociedad y cultura: general" y JP "Política y gobierno", mientras que los textos filosóficos se ubican en la categoría de materia $\mathrm{H}$ "Humanidades (historia, arqueología, filosofía y religión)", identificados más concretamente con el código de materia HP "Filosofía".

La producción editorial de libros en España entre los años 2009 a 2013 en estas materias así clasificadas bajan su edición entre el $10 \%$ y el $20 \%$ según datos del Ministerio de Educación, Cultura y Deporte (MECD, 2014, 50/58), en cuyo informe se recoge específicamente que la publicación de libros de ciencias sociales y humanidades experimenta un descenso en su edición del $16,6 \%$, lo que supone un descenso similar al que sufren los libros de texto $(15,8 \%)$ y los libros de creación literaria $(12,4$ $\%)$, pero inferior al de los libros científicos y técnicos $(30,2 \%)$ y superior al de los libros infantiles y juveniles $(8,2 \%)$. Solo los libros integrados en el subsector de edición catalogado como "Otros" (religión y teología y arte y ciencia militar) aumentan su número de registros en el año 2013 en un 3,6 \% .

Los descensos en la edición se producen en todas las materias incluidas en el subsector de libros de ciencias sociales y humanidades, pero principalmente en aquellas relativas a la enseñanza y la educación (39,7\%), la geografía y los viajes $(20,5 \%)$, la etnografía, los usos y las costumbres, el folclore $(18,9 \%)$, la sociología y la estadística $(18,8 \%)$ y las obras de referencia y consulta $(18,6 \%)$.

Esta misma fuente (MECD, 51-52, 59/78) revela que el subsector de libros de ciencias sociales y humanidades es el segundo subsector con precios más elevados en el mercado, solo detrás del subsector de libros científicos y técnicos, y ofrece libros con un precio medio de 25,34 euros por ejemplar de una media de 273 páginas. El encarecimiento del precio de venta de estos libros puede explicar en parte el descenso de su producción si se tiene en cuenta el especial periodo de crisis económica internacional que vive España en los últimos años.

La edición en soportes distintos al papel (grabaciones sonoras, videograbaciones, diapositivas y microformas) representa el 26,0 
\% del total y la edición electrónica (soportes informáticos, archivos de Internet y libros digitales) el 25,9 \%, lo que refleja el paulatino aumento de interés de los receptores por nuevos formatos de publicación. El formato de libro electrónico más utilizado es el Pdf (3624 ISBN), seguido del ePub (1849 ISBN). Los libros acompañados de material multimedia, principalmente CD-ROM o CD-I, disquete o disco compacto, descienden, sin embargo, un $29 \%$.

La mayor incidencia de edición institucional se produce en los libros científicos y técnicos $(19,8 \%)$ y en los libros de ciencias sociales y humanidades $(17,0 \%)$, de lo que se colige que el emisor de este tipo de textos tiene un alto grado de especialización de conocimientos y el receptor también lo tiene o aspira a tenerlo. En este sentido, la función principalmente didáctica de estos textos queda demostrada.

No obstante, por encima de los agentes editores institucionales, las editoriales medianas $(31,89 \%)$, pequeñas $(25,90 \%)$ y grandes $(18,35 \%)$ son las que más publican este tipo de textos, con sedes editoriales en Madrid (38,9 \%) y en Barcelona (25,5 \%), seguidas muy de lejos por editoriales con sedes en Andalucía $(9,5 \%$ ) y Comunidad Valenciana $(7,9 \%)$.

El MECD (2014, 130/132) detalla las veinticinco mayores empresas editoras por materias, siendo las tres primeras editoriales para la materia 2 "Filosofía y psicología" la Editorial Desclée de Brouwer, la Editorial Kairós y Herder Editorial y para la materia 4 "Sociología y estadística" Ediciones Paidós Ibérica, Universitat Autònoma de Barcelona y Espasa Libros. Es interesante destacar que la plataforma virtual de autoedición Bubok se sitúa en los puestos 7 y 13, para cada materia respectivamente, lo que confirma la tendencia actual hacia un medio que resulta rentable económicamente para los autores y con plazos de publicación más cortos.

En relación con la traducción de libros, el MECD (28-29) constata que las traducciones suponen el $22,3 \%$ del total de la producción editorial española, si bien en el año 2013 las traducciones descienden un 13,9 \% con respecto al año 2012. Como analiza el Observatorio de la Lectura y el Libro (OLL, 2014, 24), en compa- 
ración con otros mercados editoriales, las traducciones en el ámbito editorial español tienen un gran peso. En Reino Unido, por ejemplo, las traducciones representan solo un $3 \%$ de su oferta editorial, dada la hegemonía del inglés como lengua internacional.

La principal lengua no española desde la que se traduce es el inglés, con un 52,3 \% del conjunto de los títulos traducidos. Le sigue el español (14,2 \%), que es la lengua más traducida al catalán (693 títulos), al vasco (287 títulos), al gallego (68 títulos) y al valenciano (73 títulos). El francés $(10,2 \%)$, el italiano $(6,2 \%)$, el alemán $(6,1 \%)$, el japonés $(2,6 \%)$, el catalán $(2,3 \%)$, el portugués $(1 \%)$, el ruso $(0,7 \%)$ y el griego $(0,7 \%)$ son el resto de lenguas traducidas de mayor frecuencia. Desde el 2009 al 2013, el inglés aumenta su porcentaje de traducciones, en tanto el resto de lenguas lo conservan o lo disminuyen con altibajos. No obstante, en España se traducen obras escritas desde más de 50 lenguas extranjeras entre las cuales se cuentan lenguas minoritarias como el hebreo, el eslovaco o el finés. De la misma manera, aunque con menor frecuencia, se traducen obras desde lenguas españolas a extranjeras (OLL, 22-26).

Cataluña (36,0 \%), País Vasco $(27,7 \%)$, Cantabria $(23,9 \%)$ y Madrid $(21,5 \%)$ son las comunidades que más libros traducidos publican sobre el total de su producción autonómica. Sobre el total de la obra traducida, Cataluña y Madrid producen el 84,7 \% de forma conjunta (OLL 2014 24).

La mayor parte de las traducciones son de libros de creación literaria $(33,7 \%)$, mientras que los libros infantiles y juveniles $(21,9$ $\%)$ y los de ciencias sociales y humanidades $(20,0 \%)$ se sitúan a la zaga (OLL, 25).

Dentro del subsector de libros de ciencias sociales y humanidades (MECD, 2014, 58-59), se traduce en el año 2013 un 14,4 \% del total de producción. Las lenguas más traducidas son el inglés (52,9 \%), el español $(13,1 \%)$, el francés $(9,5 \%)$ y el alemán $(9,4 \%)$. 


\subsection{Competencias profesionales del traductor}

Como el OLL (24) pone de manifiesto:

Al margen de las oscilaciones interanuales, a tenor de las cifras recogidas año tras año, puede decirse que el traductor constituye un eslabón imprescindible en la transmisión del saber y la cultura, con un papel social y cultural de primera línea. Su contribución se extiende también al ámbito económico: el traductor es, además de lo anterior, un generador de riqueza para la industria editorial, aunque a priori una traducción implique un coste añadido en el proceso de publicación de cualquier libro.

De ambas funciones del traductor dentro del mercado editorial español actual es consciente la Sección Autónoma de Traductores de Libros de la Asociación Colegial de Escritores de España (ACE Traductores, 2010, 37), quien expone la situación laboral del traductor de libros en España a partir de datos objetivos obtenidos en una encuesta realizada a traductores y analizada estadísticamente con la finalidad de establecer "unas bases, cognitivas y prácticas, orientadas a actuar, a mejorar la situación actual de quienes traducen en España". ${ }^{2}$

El perfil básico de los traductores dedicados a la traducción de libros en general y de libros de ciencias sociales y humanidades en particular es el de hombres $(45,9 \%)$ y mujeres $(54,1 \%)$ de una media de edad de cuarenta y seis años con una formación mayoritaria en traducción $(29,8 \%)$ y filologías $(28,0 \%)$ que no se dedican en exclusiva a la traducción $(62,5 \%)$ y que compaginan su ejercicio traductor con la docencia no universitaria $(40,1 \%)$ y con la creación literaria $(28,1 \%)$ principalmente. Llevan en el oficio más de veinte años $(22,6 \%)$ y son autónomos $(49,5 \%)$ o no $(50,5$ $\%$ ) por igual (ACE Traductores, 2010, pp.47-51). Los traductores trabajan con a partir de una lengua original (36,5\%), de dos lenguas originales $(27,9 \%)$ e incluso de tres lenguas originales o más 
$(35,7 \%)$ (ACE Traductores, 55) en los porcentajes de producción de traducciones de libros según los datos aportados por el MECD (2014) y el OLL (2014). Asimismo, la media de editoriales por traductor es de $2,35 \%$ y solo un $6,2 \%$ de los traductores mantiene su unidad familiar exclusivamente con los ingresos procedentes de la traducción de libros (ACE Traductores, 54/59).

Para desarrollar su trabajo con éxito en un mercado editorial concreto, el traductor de textos sociopolíticos y filosóficos del perfil anteriormente descrito debe poner en práctica una serie de habilidades y destrezas relacionadas directamente con las características específicas de los textos con los que trabaja, de gran carga cultural e ideológica, pero también con el entorno laboral en el que se inscribe su actividad. Se podría hablar, entonces, de un conocimiento genérico complementado por un conocimiento profesional. $\mathrm{Su}$ competencia traductora general debe orientarse, por tanto, de forma muy específica al contexto profesional de la traducción de textos sociopolíticos y filosóficos. En este sentido es interesante tener en cuenta, por un lado, los rasgos principales que definen el perfil profesional del traductor de libros y, por otro lado, la forma de adquisición de esos rasgos.

En relación con las características principales del traductor profesional de libros, Muñoz Raya $(2004,74)$ enumera las siguientes para el traductor profesional generalista, tomadas como base para la elaboración de los planes de estudio universitarios de formación de traductores e intérpretes en España que rigen actualmente: interés por las lenguas y las culturas, dominio perfecto de la lengua materna y de sus variedades, conocimiento profundo de las lenguas originales y dominio de las herramientas informáticas profesionales. Añade, además, otros rasgos psicológicos como son la flexibilidad mental y la capacidad de adaptación a entornos profesionales variables, la capacidad de trabajar en equipo, la meticulosidad, la curiosidad intelectual y el conocimiento de los límites propios. Si bien la actividad traductora en el ámbito de los textos sociopolíticos y filosóficos pudiera localizarse exclusivamente en el perfil profesional del traductor generalista, una visión más completa del trabajo objetivo 
del traductor de estos textos debería incluir otros rasgos que Muñoz Raya (74) enumera entre los que se le exigen al traductor profesional especializado, a saber, poseer conocimientos especializados en su materia y en el lenguaje propio de la misma, poseer competencias de gestión profesional, investigación y terminología aplicada, saber gestionar su tiempo a fin de cumplir escrupulosamente con los plazos establecidos y saber gestionar proyectos.

Por cuanto afecta a la manera en que se adquieren estas destrezas, Kiraly (2013 206-214) propone un modelo en cuatro dimensiones que entiende la adquisición de la competencia traductora como el resultado de un proceso en el que la competencia traductora emerge a partir de las conexiones que las diferentes subcompetencias realizan entre sí a lo largo del tiempo de formación y práctica. El aspecto interpersonal influye, además, en este proceso, de tal manera que cada traductor modela su competencia traductora en el tiempo en relación con las conexiones que mantenga con los agentes implicados en el proceso de traducción. De ahí que el acercamiento que Muñoz Raya (104) propone al mercado profesional a la luz de las encuestas realizadas a empleadores y asociaciones profesionales se convierta en pilar fundamental para la formación del traductor e intérprete en general y del traductor de textos sociopolíticos y filosóficos en particular.

Este modelo de competencia traductora resulta de gran interés para el análisis de la práctica profesional de la traducción de textos sociopolíticos y filosóficos, ya que en este campo especializado de la traducción confluyen determinadas características marcadas por el entorno profesional que definen las competencias profesionales que debe alcanzar el traductor.

\subsection{Retos traductores prácticos}

El proceso de traducción de los textos sociopolíticos y filosóficos se enfrenta en su práctica profesional a múltiples retos traductores derivados de las circunstancias competenciales anteriormente 
detalladas y de las demandas editoriales del mercado español actual. Entre aquellos que diferencian la traducción de estos textos de la traducción de otros textos humanísticos se hallan los siguientes: la diacronía en traducción, los métodos traductores, los nuevos formatos de publicación y la oralidad en traducción.

\subsubsection{Diacronía en traducción}

La traducción de textos producidos en sus lenguas originales con bastante anterioridad en el tiempo al momento de su traducción supone un reto traductor importante. No en vano, como afirma Hurtado Albir $(2001,597)$, "Todo texto es fruto de su época", y, por lo tanto, se supedita a los condicionantes de la misma. Este reto traductor está presente sobre todo en encargos de traducción relacionados con textos filosóficos.

Si bien las tres principales empresas editoras para la materia 2 "Filosofía y psicología” según el MECD (2014, 130), la Editorial Desclée de Brouwer, la Editorial Kairós y Herder Editorial, cuentan entre sus colecciones dedicadas específicamente a la filosofía con textos extranjeros en su totalidad contemporáneos, otras editoriales tienen entre sus catálogos colecciones expresamente compuestas por libros clásicos retraducidos. Es el caso, por ejemplo, de la Editorial Tecnos, ${ }^{3}$ que cuenta con dos colecciones, Clásicos del Pensamiento y Esenciales de la Filosofía, en las que se agrupan obras y autores principales de la historia de la filosofía y la política. Su catálogo actual de clásicos extranjeros asciende a 166 títulos, entre los cuales se encuentran filósofos que escribían originalmente en una gran diversidad de lenguas: Han Fei Zi, Kant, Locke, Maquiavelo, Platón o Rousseau son algunos nombres propios, entre muchos otros.

Estas traducciones son, por lo general, retraducciones surgidas de la necesidad de la actualización de la traducción anterior para su aceptación por parte del receptor actual. La nueva traducción debe vertebrarse a partir de la reflexión sobre acercar la traducción al receptor actual o mantenerla según el receptor que la traduc- 
ción habría tenido de haberse realizado al publicarse por primera vez el texto original. Esta decisión corresponde tomarla en última instancia a la editorial en función del receptor pretendido, pero es responsabilidad del traductor ofrecer ambas posibilidades antes de acometer el proceso traductor. La tendencia en nuestros días es a actualizar la expresión utilizada en la lengua de traducción con mayor o menor número de amplificaciones en el texto o fuera de él, en forma de paratextos.

\subsubsection{Métodos traductores}

El método traductor, entendido como la aproximación global a la traducción que realiza el traductor y que define las técnicas y estrategias de traducción que aplica en su proceso de traducción (Hurtado Albir, 241), puede variar en función de los encargos de traducción dentro de campos temáticos que tienen una marcada finalidad didáctica. Es el caso principalmente de textos filosóficos, ya que este campo temático es objeto de formación académica reglada desde estadios muy tempranos y objeto de especialización académica en estadios superiores.

Si se toma como referencia una obra filosófica a medio camino entre género narrativo y humanístico, El mundo de Sofía del escritor noruego Jostein Gaarder (1991), se puede observar la variación de métodos traductores en función de los receptores pretendidos. Ediciones Siruela continúa reeditando hasta el presente año 2015 la traducción de este libro, ${ }^{4}$ pero fragmentos del mismo se incluyen en muchos libros de texto de Bachillerato que publican diversas editoriales (por ejemplo, Editex ${ }^{5}$ ), se ha adaptado su contenido traducido a un programa interactivo publicado por Anaya Multimedia ${ }^{6}$ y una traducción audiovisual para el cine se realizó para el receptor más general en 1999.7

Cada editorial así como la productora de cine tienen un receptor pretendido diferente, por lo que el traductor debe optar por un método traductor distinto en cada caso. Siguiendo las denominaciones de Hurtado Albir (252), en el primer encargo, el método traductor 
puede ser el literal o el filológico, con explicaciones eruditas de conceptos temáticos complejos; en el segundo encargo se debe optar por un método traductor interpretativo-comunicativo que cuente con amplificaciones en el texto tanto de los culturemas como de la terminología propia del ámbito de especialización filosófico, y en el tercer y en el cuarto encargo se tendría que tener en cuentas las particularidades propias de la traducción multimedia y audiovisual como modalidad de traducción específica.

\subsubsection{Formatos de publicación}

Los formatos de publicación varían en función de las necesidades de un mercado editorial en continuo cambio. Los textos sociopolíticos, producidos desde el ser humano sobre el ser humano y para el ser humano, y con un alto grado de potencial interés del público general, requieren del traductor su adaptación a nuevas formas de difusión del conocimiento diferentes a las tradicionales.

En este sentido, si se analizan los catálogos de las editoriales que el MECD (132) detalla como las veinticinco mayores empresas editoras para la materia 4 "Sociología y estadística", se encuentran con frecuencia libros de temática sociopolítica que suponen una síntesis de textos originariamente publicados en otros formatos. Ediciones Paidós Ibérica ${ }^{8}$ bajo la temática de pensamiento político, ofrece un claro ejemplo de esta costumbre editorial. La periodista canadiense Naomi Klein publica en 2002 una recopilación de sus ensayos y trabajos periodísticos, Vallas y ventanas: despachos desde las trincheras del debate sobre la globalización. Algunos de estos trabajos son inéditos, pero otros fueron publicados previamente en medios de comunicación social tradicionales (periódicos) o de reciente creación en los últimos años (página web de la autora).

La traducción se convierte en un camino de ida y vuelta entre formatos de publicación diferentes cuyas especiales características pueden incluso repercutir en el contenido. De esta forma, los límites entre los géneros textuales se diluyen y el traductor de estos textos debe ampliar sus destrezas a aquellas que son requeridas por 
traducciones de tipologías textuales diferentes a las que tradicionalmente daban cobijo a textos sociopolíticos. Cuestiones de formato e instrumentales, que pueden incluso llegar a la localización, cobran aquí especial importancia, además de las cuestiones lingüísticas y discursivas propias de los géneros textuales originarios.

\subsubsection{Oralidad en traducción}

Los textos sociopolíticos son en muchas ocasiones escritos para presentación oral, por lo que sus convenciones discursivas navegan entre las propias del discurso escrito y las del discurso oral. Los discursos políticos dan buena cuenta de esta característica. Dadas las restricciones de las políticas de los derechos de autor, muchos de estos discursos se fragmentan en publicaciones que reflexionan sobre la ideología subyacente en los discursos del orador o sobre la propia figura del orador y su influencia en el panorama político (inter)nacional. No obstante, los fragmentos no dejan de ser traducciones contextualizadas de un discurso oral que busca la perdurabilidad escrita.

Buen ejemplo de esto es el libro editado, y traducido, por Joan Gomis en 2013 sobre la figura de Martin Luther King, Un sueño de igualdad, publicado en Los Libros de la Catarata. ${ }^{9}$ En estos casos, las reglas discursivas concernientes a la retórica del discurso se deben tener en cuenta en la traducción, además de las propias de las características textuales de los textos sociopolíticos. En traducciones de discursos políticos de gran calado se deben considerar, igualmente, las traducciones anteriores realizadas del mismo texto original, ya sea en la forma de otros libros editados, ya sea en otras formas de traducción audiovisual (subtitulación, doblaje o voz superpuesta en noticias, películas y documentales) e incluso en la forma de interpretación simultánea en casos más actuales. Todas estas (re)traducciones servirán como corpus documental de la nueva traducción. 


\section{En conclusión: traducción y profesión}

La traducción de textos sociopolíticos y filosóficos debe adaptarse al entorno laboral en el que se produce como actividad editorial. Para el traductor de este tipo de textos resulta de especial importancia conocer las características genéricas que definen al material con el que trabaja, de gran carga cultural e ideológica, pero también debe estar al día de los condicionantes laborales en los que ejerce su profesión, puesto que estos determinan tareas traductoras relacionadas con el contexto en el que se lleva a cabo la traducción y con los participantes en este proceso traductor. La unión de ambos conocimientos favorece una competencia traductora global que permite al traductor desarrollar su labor con éxito y estar en disposición de reivindicar mejoras en el ejercicio de su profesión. ${ }^{10}$

\section{Notas}

1. Véanse las páginas web de la Federación de Gremios de Editores de España http://www.federacioneditores.org/, de la Agencia Española del ISBN http:// agenciaisbn.es/web/comunicacion.php y del Distribuidor de información del libro español en venta http://www.dilve.es/dilve/dilveweb/dilve_IBIC.jsp para más información al respecto de la adopción de este nuevo sistema de catalogación por materias.

2. Otros estudios que también han versado sobre la situación profesional del traductor de libros, son, por orden cronológico: ACE Traductores. Libro Blanco de la traducción en España. Madrid: ACE Traductores, 1997; Rodríguez Morató, Arturo. La problemática profesional de los escritores y traductores. Una visión sociológica. Barcelona: ACEC, 1997; Escobar, Julia. "La traducción y la interpretación en español". El español en el mundo. Anuario del Instituto Cervantes. 
Dirección Académica del Instituto Cervantes, coordinación. Madrid: Arco Libros-Instituto Cervantes, 1998. 13-57; ACE Traductores. "Informe sobre la situación del traductor de libros en España”, Vasos comunicantes 25 (2003): 39-64.

3. Véase la página web de la Editorial Tecnos http://www.tecnos.es/listado. php?origen $=$ menu\&id_clase $=219145 \&$ pagina $=1$.

4. Véase la página web de Ediciones Siruela http://www.siruela.com/catalogo. php?id_libro $=2783 \&$ completa $=$ S.

5. Véase la página web de la editorial Editex http://www.editex.es/publicacion/ filosofia-y-ciudadania- $1^{\mathrm{O}}$-bachillerato-438.aspx.

6. Véase la página web de la editorial Anaya Multimedia http://www.anayamultimedia.es/index.php.

7. Véase la ficha técnica de la película http://www.filmaffinity.com/es/ film476220.html.

8. Véase la página web de la Editorial Paidós Ibérica http://www.planetadelibros. com/index.php?tipo $=$ editoriales $\&$ nombre $=$ ediciones-paidos\&ed $=3 \&$ pagina $=c a$ talogo\&filtrado $=$ si

9. Véase la página web de la editorial Los Libros de la Catarata http://www. loslibrosdelacatarata.org/libro/mostrar/id/19.

10. Véase PETRA. De camino hacia unas nuevas condiciones para la traducción literaria en Europa. [en línea]. 2011. Disponible en: https://www.dropbox. $\mathrm{com} / \mathrm{s} / \mathrm{dgbwg} 8$ uxedmhz64/RecomendacionesPETRA.pdf?dl =0 [Consulta 29 enero 2015] para tener una visión general sobre las demandas de los traductores literarios a nivel europeo. 


\section{Referencias}

ACE Traductores. Libro Blanco de la traducción en España. [en línea]. 2010. Disponible en: http://www.ace-traductores.org/libro_blanco [Consulta 29 enero 2015].

Eco, Umberto. Obra abierta. 1962. Traducido del italiano por R. Berdagué. Barcelona: Ariel, 1990.

Enríquez-Aranda, Mercedes; Mendoza García, Inmaculada. "Los géneros literarios y la traducción. Aproximación a nuevas formas de creación literaria y traducción en tiempos de crisis", Futhark 9 (2014): en prensa.

Federación de Gremios de Editores de España. IBIC. Sistema de clasificación de materias. [en línea]. 2011. Disponible en: http://www.dilve.es/dilve/dilveweb/dilve_IBIC.jsp [Consulta 29 enero 2015].

García Berrio, Antonio; Huerta Calvo, Javier. Los géneros literarios: sistema e historia. Madrid: Cátedra, 1992.

Hurtado Albir, Amparo. Traducción y Traductología. Introducción a la Traductología. Madrid: Cátedra, 2001.

Kiraly, Don. "Towards A View of Translator Competence as an Emergent Phenomenon: Thinking Outside the Box(es) in Translator Education". New Prospects and Perspectives for Educating Language Mediators. Don Kiraly, Silvia Hansen-Schirra y Karin Maksymski, editores. Tubinga: Narr Verlag, 2013. 197-224.

Ministerio de Educación, Cultura y Deporte. Panorámica de la edición española de libros 2013. Análisis sectorial del libro (PeEl). [en línea]. 2014. Disponible en: https://sede.educacion.gob.es/publiventa/detalle.action?cod=20009C [Consulta 29 enero 2015].

Muñoz Raya, Eva; coord. Libro Blanco. Título de Grado en Traducción e Interpretación. [en línea]. 2004. Disponible en: http://www.aneca.es/media/150288/ libroblanco_traduc_def.pdf [Consulta 29 enero 2015]. 
Observatorio de la Lectura y el Libro. El sector del libro en España 2012-2014. [en línea]. 2014. Disponible en: http://www.mecd.gob.es/dms/mecd/cultura-mecd/areas-cultura/libro/mc/observatoriolect/redirige/destacados/mundo-libro/ Informe-sectorlibro/El-Sector-del-libro-en-Espa-a-/El \%20Sector \%20del \%20 libro \%20en \%20Espa \%C3 \%B1a \%20.pdf [Consulta 29 enero 2015].

Recebido em: 03/01/2015

Aceito em: 17/03/2015 